\title{
¿RE OBLIGAMUR, CUM RES IPSA INTERCEDIT? SOBRE EL ASÍ LLAMADO CONTRATO REAL EN MODESTINO
}

\author{
RE OBLIGAMUR, CUM RES IPSA INTERCEDIT? \\ ON THE SO-CALLED REAL CONTRACT BY MODESTINUS
}

\begin{abstract}
Adolfo Wegmann Stockebrand*
RESUMEN: Este artículo aborda el problema de la amplísima noción de re obligari contenida en los libri regularum del jurista romano Herenio Modestino: re obligamur, cum res ipsa intercedit. De los términos empleados por Modestino pareciera derivarse un concepto de obligación real que se identifica con toda obligación que se contrae por medio de la entrega de una cosa, es decir, una figura que en lo fundamental correspondería al moderno concepto de contrato real. Sin embargo, un atento análisis de la obra de este jurista demuestra que su noción de re obligari se encontraba restringida al mutuum, único supuesto de obligatio re contracta en el derecho romano clásico.
\end{abstract}

Palabras clave: Obligatio re contracta, contrato real, mutuo, Modestino.

ABSTRACT: This paper deals with the issue of the broad notion of re obligari included in the libri regularum of the Roman jurist Herennius Modestinus: re obligamur, cum res ipsa intercedit. From the terms used by Modestinus seems to stem a concept of real obligation that corresponds to any obligation acquired by the delivery of a thing; that is, a notion which would essentially correspond with the modern concept of a 'real contract'. However, careful analysis of this jurist's work shows that his notion of re obligari was restricted to mutuum, the only case of obligatio re contracta that existed in classical Roman law.

Key words: Obligatio re contracta, real contract, loan, Modestinus.

\section{INTRODUCCIÓN}

La categoría de los contratos reales es una noción conceptual y sistemática propia de la tradición jurídica europea-continental, de la cual Chile es heredero ${ }^{1}$. En efecto, la mayoría de los ordenamientos jurídicos que forman parte de esta tradición reconoce en la entrega de una cosa (implique o no transferencia de dominio) el modo de perfeccionamiento

\footnotetext{
Doctor en Derecho, Profesor de Derecho Privado (Derecho Romano y Derecho Civil), Facultad de Derecho, Pontificia Universidad Católica de Chile. Dirección postal: Avenida Libertador Bernardo O’Higgins 340, Santiago, Chile. Dirección electrónica: aawegman@uc.cl. Este artículo forma parte del proyecto Fondecyt de Iniciación en Investigación No 11170478 Aliud est enim credere, aliud deponere. Sobre la relación entre causas crediticias y depósito en el derecho romano clásico, del cual el autor es investigador responsable.

1 En este sentido especialmente Maschi (1973) p. 1. Véase también p. ej. Bussi (1939) pp. 7 ss.; Verdam (1953) pp. 745 ss.; Coing (1985) pp. 469 ss.; Zimmermann (1996) pp. 153 ss.
} 
de ciertos contratos ${ }^{2}$ de los cuales emana como obligación principal la de restituir la misma cosa (res ipsa), como es el caso del comodato, el depósito y la prenda, o bien, otro tanto del mismo género y calidad (tantundem eiusdem generis et qualitatis), como ocurre respecto del mutuo ${ }^{3}$. Expresado en otros términos: la entrega de la cosa no opera solvendi causa, es decir, como cumplimiento de una obligación previamente contraída, sino contrahendi causa, como acto constitutivo del vínculo jurídico. En este contexto, los códigos civiles del área germánica (BGB alemán, ABGB austríaco y ZGB suizo) son la excepción, toda vez que han suprimido la categoría de los contratos reales en todo o parte, atribuyendo naturaleza consensual a todas o algunas de las figuras que la conformarían ${ }^{4}$.

En trabajos anteriores hemos intentado demostrar que el derecho romano clásico conoció una única causa de obligatio re contracta (término del cual deriva el contractus re del ius commune y el consiguiente contrato real moderno), a saber, la mutui datio, limitando la noción del así llamado contrato real romano al mutuo y, por tanto, a una entrega translaticia de dominio (datio rei): re contrahitur obligatio mutui datione. Lo anterior se aprecia no solo en Gayo (tanto en sus Institutiones ${ }^{5}$ como en las res cottidianae ${ }^{6}$ ), sino que también en Quinto Mucio Escévola (según el testimonio de Pomponio) ${ }^{7}$ y en Paulo ${ }^{8}$. Incluso las Instituciones de Justiniano parecieran -si no en la interpretatio bizantina, al menos en la letra de los textos- confirmar esta misma doctrina?.

En el presente estudio pretendemos abordar el problema de la amplísima noción de re obligari contenida en los libri regularum del jurista tardo-clásico Herenio Modestino, según la cual una obligación nacería re cada vez que concurre la entrega de una cosa: re obli-

\footnotetext{
2 Si bien en doctrina se suele hablar en términos de perfeccionamiento del contrato, se trata de una nomenclatura del todo ajena al pensamiento romano, que daba al sintagma contrahere obligationem un sentido diverso, referido más bien al acto material concreto que engendraba la obligación (su causa), que no es lo mismo exactamente. Véase al respecto Falcone (2011) p. 30; Brasiello (1944) p. 103. En detalle sobre esta cuestión, desde la perspectiva del autor, Wegmann Stockebrand (2017a) pp. 69 ss.; Wegmann Stockebrand (2019a) en prensas.

3 Así ocurre en la mayoría de los códigos civiles, que establecen que ciertos contratos se perfeccionan mediante la entrega de una cosa, sin otorgarles explícitamente la denominación de contratos reales. Véase por ejemplo el Code Civil francés: art. 1875 (comodato), 1892 (mutuo), 1915 (depósito) y (desde la reforma de 2006) 2011 (fiducia); el Codice Civile italiano: art. 1766 (depósito), 1803 (comodato), 1813 (mutuo) y 2786 (prenda); el Código Civil español: art. 1740 (mutuo y comodato), 1758 (depósito) y 1863 (prenda). El Código Civil chileno, en cambio, habla en términos explícitos de contrato real en su art. 1443: El contrato es real cuando, para que sea perfecto, es necesaria la tradición de la cosa a que se refiere (...).

4 Véase $\$ \$ 488$ (mutuo de dinero), 598 (comodato), 607 (mutuo de cosas fungibles distintas del dinero) y 688 (depósito) del BGB; $\$ 983$ (mutuo) del ABGB; art. 305 (comodato), 312 (mutuo) y 472 (depósito) del ZGB. En cambio, tanto el depósito (\$957) como el comodato (\$971) siguen estando configurados como contratos reales en el ABGB.

5 Gai. 3,90. Véase, desde la perspectiva del autor, Wegmann Stockebrand (2017a) pp. 115 ss; Wegmann STOCKebrand (2018) pp. 97 ss.

6 D. 44,7,1,2 (Gai. 2 res cott.). Véase, desde la perspectiva del autor, Wegmann Stockebrand (2017a) pp. 183 ss., 218 ss.; Wegmann Stockebrand (2019b) en prensas.

7 D. 46,3,80 (Pomp. 4 ad Q. Muc.). Véase, desde la perspectiva del autor, Wegmann Stockebrand (2017a) pp. 34 ss.; Wegmann STOCKebrand (2018) pp. 109 ss.

8 D. 2,14,17pr. (Paul 3 ad ed.). Véase, desde la perspectiva del autor, Wegmann STOCKEBrand (2017a) pp. 179 ss; Wegmann Stockebrand (2018) pp. 113 ss.

9 I. 3,14pr. Véase, desde la perspectiva del autor, Wegmann Stockebrand (2017a) pp. 236 ss.
} 
gamur, cum res ipsa intercedit ${ }^{10}$. De los términos empleados por Modestino pareciera derivarse a primera vista un concepto de obligación (contractual) real muy distinta de la recién esbozada, ya que se identificaría sin más con todos aquellos casos en los cuales la constitución del vínculo obligatorio supone el acto material de entrega de una cosa, vale decir, una figura que en lo fundamental correspondería al moderno concepto de contrato real arriba mencionado, entendido como aquel que se perfecciona mediante traditio en sentido lato, con independencia de que esta suponga o no una transferencia de dominio.

Si bien no podemos negar la desprolijidad con la cual Modestino se refiere en su obra a la naturaleza del re obligari, creemos que no hay en esta ni en otras fuentes argumentos textuales que permitan sostener que el jurista extendió tal género obligacional y, con ello, el re contrahere, a negocios distintos de la mutui datio. Más bien todo lo contrario: a partir de la exégesis del fragmento resulta que Modestino no ofrece novedades en lo que respecta a la estructura de la obligatio re contracta clásica, siempre restringida al mutuum.

Nuestro plan de trabajo exige, pues, referirse primera y someramente a la individualidad de Modestino en el marco de la jurisprudencia tardo-clásica (1), para luego abordar la cuestión del campo semántico del concepto técnico obligatio re contracta en el derecho romano clásico (2). Lo anterior nos permitirá contrastar dicha noción con la idea de re obligari contenida en D. 44,7,52,1, a partir de la exégesis del fragmento (3), y extraer de ello conclusiones sobre el así llamado contrato real en el pensamiento de Modestino, además de perspectivas de investigación.

\section{LA INDIVIDUALIDAD DE MODESTINO}

Los juristas romanos no son fungibles, y su individualidad histórica resulta indispensable a la hora de intentar reconstruir su pensamiento y juzgar en qué medida y de qué manera contribuyeron a la formación de aquello que, retrospectivamente, solemos denominar como derecho romano clásico ${ }^{11}$. El jurista tardo-clásico Herenio Modestino ciertamente no es la excepción. Él ha pasado a la historia del derecho romano principalmente por dos motivos, ambos más bien ajenos a su propia voluntad: por una parte, es considerado habitualmente como el último jurista clásico ${ }^{12}$; por la otra, tuvo la suerte de ser incluido, junto a su maestro Ulpiano ${ }^{13}$ y a Paulo, Papiniano y Gayo en el selecto club de las cinco auctoritates de la así llamada Ley de Citas del año 426, en virtud de la cual sus escritos pasaron a ser considerados como jurídicamente vinculantes ${ }^{14}$. Lo anterior dice mucho sobre la alta consi-

\footnotetext{
10 D. 44,7,52,1 (Mod. 2 reg.). Una exégesis detallada de la fuente infra, 3.

$11 \mathrm{Al}$ respecto véase por ejemplo BaLdus (2012) pp. 7 ss.

12 Véase p. ej. Brassloff (1912) pp. 667, 674; Orestano (1964) p. 819; Kunkel (1967) p. 259; GómezIGLESIAS (2004) p. 214.

13 El hecho que Modestino fue discípulo de Ulpiano es indudable, puesto que es mencionado como tal por este último, con motivo de una consulta que le dirigió nuestro jurista desde Dalmacia, conservada en D. 47,2,52,20 (Ulp. 37 ad ed.). De ahí que algunos hayan planteado la hipótesis de que Dalmacia pudo ser la patria del jurista. Cf. KunKel (1967) p. 259. Para un estudio más detallado sobre la relación entre Ulpiano y Modestino, que escapa de los márgenes de este trabajo, nos remitimos a VIARENGO (2009a) pp. 56 ss. y la bibliografía por ella citada.

14 CTh. 1,4,3.
} 
deración en la que se debió tener a Modestino en época postclásica; de hecho, el emperador Gordiano III (238-244) no dudó en calificarlo como un jurista de indiscutida autoridad ${ }^{15}$.

Los compiladores justinianeos conservaron en el Digesto un total de 347 fragmentos extraídos de las obras de Modestino ${ }^{16}$, a los cuales debemos añadir un texto en el que Arcadio Carisio se remite en términos explícitos a él ${ }^{17}$. Ciertamente tenemos en frente una cantidad relativamente pequeña de testimonios textuales, si la comparamos con la de otros juristas tardo-clásicos; para qué decir con Ulpiano, quien por sí solo representa aproximadamente la tercera parte del Digesto. No obstante lo anterior, es suficiente para formarse una impresión general sobre el papel desempeñado por Modestino en el seno de la jurisprudencia del siglo III d.C. ${ }^{18}$. Sorprendentemente, lo dicho no ha logrado despertar en la romanística moderna demasiado interés en su persona y obra: tradicionalmente la doctrina ha menospreciado el trabajo de Modestino, al considerarlo un jurista más bien mediocre, siempre a la sombra de su gran maestro.

La única obra de su autoría que ha sido objeto de acucioso estudio por parte de la moderna ciencia romanística es su monografía, redactada íntegramente en griego y de índole eminentemente práctica, sobre las excusas para ser tutor, cuyo título fue traducido por los compiladores como libri de excusationibus ${ }^{19}$. De su contenido se desprende que con toda probabilidad estuvo destinada a la práctica forense en materia de tutela en una provincia romana de cultura helenística. Los demás escritos de Modestino, entre otros (junto a monografías sobre cuestiones específicas) sus Pandectae, Differentiae, Responsae y las -muy importantes para nuestro estudio- Regulae, todavía esperan, como señaló Schulz hace ya varias décadas, una investigación crítica detallada ${ }^{20}$.

Sabemos muy poco sobre la vida y el origen de Modestino. Nuestros datos sobre su vida profesional se limitan básicamente a que llegó a desempeñar el cargo de praefectus vigilum $^{21}$ y fue preceptor del hijo del emperador Maximinus Thrax, C. Iulius Verus Maximinus $^{22}$. Como jurista se encontraba activo todavía el año 239, según el elogioso testimonio de Gordiano III ya citado ${ }^{23}$. Mucho más difícil es conjeturar sobre su origen, ya que las fuentes no nos ofrecen antecedentes fidedignos al respecto ${ }^{24}$ : su nombre no ayuda

\footnotetext{
15 C. 3,42,5 (Gord., a. 239): Ad exhibendum actione non tantum eum qui possidet, sed etiam eum teneri, qui dolo fecit, quominus exhiberet, merito tibi a non contemnendae auctoritatis iuris consulto Modestino responsum est. Véase también C. 3,28,36,2 (Iust., a. 531).

16 Cf. Lenel (1889) pp. 701 ss.

17 D. 50,4,18,26 (Arc. Char. l.s. de mun. civ.). Sobre la vinculación entre ambos juristas Viarengo (2009a) pp. 205 ss.

18 Una visión de conjunto sobre la posición de Modestino dentro de la jurisprudencia tardo-clásica en HonORÉ (1962) pp. 213 ss.

19 Lenel (1989) pp. 707 ss. Un detallado análisis monográfico de la obra en Masiello (1983). Véase también Viarengo (1996); Volterra (1970) pp. 583 ss.; Altmann (1955) pp. 1 ss.; Peters (1912) pp. 511 ss.

20 Schulz (1961) p. 224. Una visión panorámica de las obras de Modestino (clasificadas según géneros literarios) en Liebs (1997) pp. 196 ss.

21 CIL VI 266 = Bruns (1909) p. 406. Detalles en Viarengo (2009a) pp. 157 ss.

22 SHA, Vita Max. 27,5. Detalles en Viarengo (2009a) pp. 177 ss.

23 C. 3,42,5 (Gord., a. 239). Detalles en Viarengo (2009a) pp. 181 ss.

24 Kunkel (1967) p. 260.
} 
demasiado, ya que si por una parte el nomen Herennius es indubitadamente itálico y se encuentra suficientemente representado durante todo el período imperial ${ }^{25}$, por otra parte, el cognomen Modestinus es comparativamente más raro, aunque aparece en las más diversas regiones del imperio ${ }^{26}$. Respecto de su praenomen, en cambio, no hay rastro alguno en las fuentes.

En doctrina se suele atribuir a Modestino una patria situada en tierras de cultura helenística ${ }^{27}$; a partir de algunos fragmentos de su monografía de excusationibus se ha querido vincularlo específicamente con el norte de Asia $\mathrm{Menor}^{28}$. Aunque no es posible afirmar con certeza que Modestino procedía de Anatolia, se puede aceptar que debió haber estado estrechamente vinculado a esta región situada en los márgenes orientales del imperio, quizá durante la mayor parte de su vida ${ }^{29}$. En todo caso, los fragmentos conservados en el Digesto permiten sostener que el jurista era un excelente conocedor tanto de la lengua griega como de la cultura jurídica del mundo helenístico bajo dominio romano, lo que en principio hablaría a favor de la tesis de un origen oriental o, por lo menos, de una estrecha relación con esa zona ${ }^{30}$. Como ya se adelantó, sus libri de excusationibus se encuentran dirigidos a satisfacer una necesidad de la práctica forense del oriente del imperio; asimismo, los libri responsorum tratan varias cuestiones de derecho propias de ese mundo, en algunos casos incluyendo citas textuales en lengua griega ${ }^{31}$. A mayor abundamiento, en sus escritos encontramos interesantísimas comparaciones entre la terminología jurídica latina y griega (apud Romanos/apud Graecos) ${ }^{32}$, así como responsae en materia de disposiciones de última voluntad redactadas en esta última lengua ${ }^{33}$.

No obstante lo anterior, las características recién esbozadas no son suficientes para extraer conclusiones firmes y más o menos concretas sobre el origen de Modestino: el recurso al idioma griego en especial y al saber de la cultura helenística en general ${ }^{34}$ era relativamente habitual incluso entre juristas que carecían de vínculos personales con oriente; de hecho, su conocimiento formaba parte del curriculum de todo ciudadano romano bien instruido (para qué decir de los prudentes) ${ }^{35}$. Basta recordar sobre este punto a Labeón, un

25 MÜNZer (1912) pp. 661 ss.

26 Kunkel (1967) p. 261; Viarengo (2009a) pp. 6 ss.

27 Así Brassloff (1912) p. 668; Peters (1912) pp. 511 ss.; Orestano (1964) p. 819; Liebs (1997) p. 195.

28 Véase D. 27,1,6,9 y 14 (Mod. 2 exc.). Cf. Peters (1912) pp. 511 ss.; KrÜger (1912) p. 253; KunKel (1967) p. 259; Liebs (1997) p. 195; Viarengo (2009a) pp. 7 ss.

29 Liebs (1997) p. 195.

30 Altmann (1955) p. 68. En detalle sobre la relación entre los juristas tardo-clásicos y las culturas jurídicas provinciales Talamanca (1976) pp. 95 ss.

31 Véase D. 31,34,1 y 7 (Mod. 10 resp.); D. 34,1,4pr. (Mod. 10 resp.) y D. 50,12,10 (Mod. 10 resp.). Cf. SCHUlz (1961) p. 321.

32 P. ej. D. 38,10,4pr.-6 (Mod. 12 pand.) en materia de relaciones de parentesco. Detalles en VIARENGO (2009a) pp. 21 ss.; VIARENGO (2009b) pp. 917 ss.

33 Así p. ej. en D. 34,1,4pr. (Mod. 10 resp.). Cf. HÄUSLER (2016) pp. 441 ss.

34 Sobre esta cuestión véase p. ej. BABUSIAUX (2014) pp. 35 ss.

35 En general sobre el bilingüismo en la antigüedad clásica y su influencia en la ciencia jurídica romana, PICHONNAZ (2017) pp. 707 ss. 
jurisconsulto de indudable origen itálico ${ }^{36}$ que, sin embargo, definió un concepto tan ro-

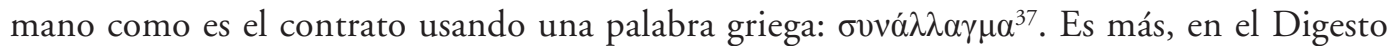
las comparaciones entre conceptos jurídicos latinos y griegos son relativamente abundantes, apareciendo no solo en la obra de Modestino y en el texto labeoniano recién referido, sino que también en Gayo y en juristas tan notables como Pomponio, Papiniano, Paulo y Ulpiano ${ }^{38}$. A mayor abundamiento, Quinto Cervidio Escévola, jurista alto-clásico de cuyo origen poco o nada se sabe ${ }^{39}$, aunque su nombre gentilicio hable más bien a favor de un origen occidental, muy a menudo se enfrenta a disposiciones de última voluntad que no solo están redactadas en lengua griega, sino que reflejan en su contenido concepciones jurídicas de claro cuño oriental ${ }^{40}$.

Por último, incluso si Modestino efectivamente estuvo estrechamente relacionado con el mundo helenístico durante parte importante de su vida profesional, esto no implica necesariamente que su vida natural haya comenzado allí. De hecho, no hay seguridad respecto a que su lengua materna haya sido el griego ${ }^{41}$ : De excusationibus es su única obra redactada íntegramente en este idioma, y ya en la dedicatoria ${ }^{42}$ deja en claro que no es fácil para él expresar conceptos jurídicos latinos en griego ${ }^{43}$, lo cual permite suponer que probablemente su lengua materna era el latín, mientras que el griego no pasaba de ser una lengua extranjera dominada en un nivel suficientemente alto, pero en ningún caso como un nativo.

En este orden de cosas, si relacionamos las características particulares de Modestino antes esbozadas con la situación cultural y jurídica del imperio a comienzos del siglo III d.C., sobre todo con posterioridad a la dictación de la así llamada constitutio Antoniniana (212), que concedió la ciudadanía romana a todos los habitantes libres del imperio, excepto los dediticios, es dable sostener que la exposición sistemática y didáctica de material jurídico romano (y, por ende, redactado originariamente en latín) en griego, debió ser una necesidad urgente considerando este radicalmente nuevo estado de cosas. Si de un día para otro millones de personas que habían nacido y se habían educado en un contexto cultural basado en la lengua y paideia griega y en conceptos jurídicos de raigambre helenística, pa-

36 Cf. KunKel (1967) pp. 32 ss.

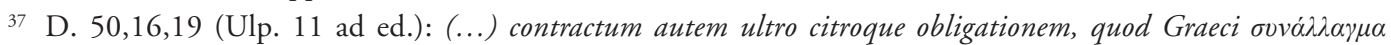
vocant (...).

38 P. ej. D. 1,16,4,5 (Ulp. 1 de off. proc.); D. 2,13,7,1 (Paul. 3 ad ed.); D. 3,2,4,1 (Ulp. 6 ad ed.); D. 11,7,42 (Flor. 7 inst.); D. 21,1,5 (Paul. 11 ad Sab.); D. 22,3,28 (Lab. 7 pith. a Paul. epit.); D. 26,7,46,1 (Paul. 9 resp.); D. 33,7,2,1 (Pap. 7 resp.); D. 38,10,10,1 (Paul. 1.s. de grad. ed adf.); D. 39,6,35,1 (Paul. 6 ad leg. Iul. et Pap.); D. 41,2,1 pr. (Paul. 54 ad ed.); D. 41,3,30pr. (Pomp. 30 ad Sab.); D. 47,2,1pr. (Paul. 39 ad ed.); D. 48,5,6,1 (Pap. 1 de adult.); D. 50,14,3 (Ulp. 8 de omn. trib.); D. 50,16,5,1 (Paul. 2 ad ed.); D. 50,16,144 (Paul. 10 leg. Iul. et Pap.); D. 50,16,163,1 (Paul. 2 ad Sab.); D. 50,16,233,2 (Gai. 1 ad leg. XII Tab.); D. 50,16,236pr.-1 (Gai. 4 ad leg. XII Tab.).

39 Sobre esta cuestión véase Kunkel (1967) pp. 217 ss.; Parma (2007) pp. 4019 ss.; Gokel (2014) pp. 68 ss.

40 Véase p. ej. D. 32,101 pr. (Scaev. 16 dig.); D. 33,4,14 (Scaev. 15 dig.); D. 34,4,30,1 y 3 (Scaev. 20 dig.) y D. 40,4,60 (Scaev. 24 dig.), fuentes donde aparecen expresamente citadas disposiciones escritas en griego.

41 Brassloff (1912) p. 674; Altmann (1955) p. 68; Viarengo (2009a) p. 5 (n. 10), 13.

42 La obra está dirigida a un tal Egnatius Dexter; D. 27,1,1pr. (Mod. 1 exc.). Podemos asumir que Egnatius Dexter tenía algún tipo de responsabilidad jurisdiccional en materia de tutela en una provincia de lengua griega. El carácter eminentemente práctico de la obra sustenta esta hipótesis. Cf. VIARENGO (2009a) pp. 10 ss.

43 D. 27,1,1,1 (Mod. 1 exc.). Cf. Schulz (1961) p. 320; Viarengo (2009a) pp. 12 ss. 
saron a estar plenamente sometidos al ius civile de la $u r b s^{44}$, debió sentirse fuertemente la necesidad de exposiciones simplificadas del conocimiento jurídico romano, adaptadas a una forma mentis a la cual aquel era más bien ajeno.

En este sentido, bien puede hablarse de una particular disposición o sensibilidad de parte de Modestino al nuevo clima surgido inmediatamente después de la dictación de la constitutio Antoniniana ${ }^{45}$. Después de todo, como él mismo expresó, Roma se había convertido en una patria común (Roma communis nostra patria est $)^{46}$, regida por un mismo derecho. La lectura de los fragmentos de Modestino conservados en el Digesto da cuenta, de hecho, de la especial preocupación de nuestro jurista ante los muy posibles malentendidos a los que podía conducir una insuficiente familiaridad con nociones jurídicas latinas, desarrolladas en un contexto geográfico, cultural, social y económico muy distinto del helenístico ${ }^{47}$. No es casualidad que sus escritos hayan sido utilizados únicamente en recopilaciones postclásicas procedentes del área oriental del imperio romano ${ }^{48}$, lo que dice bastante a favor de la tesis de cierto distanciamiento del así llamado derecho vulgar de la mitad occidental del imperio respecto del pensamiento de Modestino ${ }^{49}$. Así las cosas, es posible plantear la hipótesis de que en sus obras de naturaleza didáctica, como es el caso de los libri regularum, Modestino pudo tener en mente principalmente a discípulos actuales o potenciales cuya lengua materna no era precisamente la de Cicerón ${ }^{50}$.

En síntesis: Si bien las fuentes no permiten afirmar con certeza de qué zona concreta del imperio romano procedía Modestino, no cabe duda de su muy especial relación con su mitad oriental, de cultura griega, así como con su práctica jurídica. Lo anterior debe ser tenido en consideración al momento de interpretar el contenido de sus escritos: por qué dijo lo que dijo, cómo lo dijo y a quién lo dijo. La noción de re obligari es, a este respecto, un muy buen ejemplo ${ }^{51}$.

\section{LA OBLIGATIO RE CONTRACTA EN EL DERECHO ROMANO CLÁSICO}

Como se adelantó en la introducción, las fuentes están contestes en cuanto a que la dación mutuaria (mutui datio) constituye la única causa de obligatio re contracta en sentido propio $^{52}$. En efecto, no hay texto romano alguno, ya sea dentro o fuera de la compilación justinianea, que emplee el sintagma re contrahere respecto de negocios distintos del mutuo.

\footnotetext{
44 Cf. Schulz (1961) p. 321; Talamanca (1976) pp. 198 ss.

45 Talamanca (1976) p. 200.

46 D. 50,1,33 (Mod. 1.s. de man.); en términos similares D. 27,1,6,11 (Mod. 2 exc.). Cf. Schulz (1934) pp. 74 ss.; Viarengo (2009a) pp. 40 ss.

47 Véase p. ej. D. 50,16,103 (Mod. 8 reg.) sobre el significado del término latino appellatio capitalis.

48 Véase p. ej. Mod. 6 diff. = Coll. 1,12,1; Mod. 2 diff. = 10,2,1-7; Mod. 2 diff. = Schol. Sin. 6; Mod. 1 reg. = Schol. Sin. 13 .

49 Esta parece ser la opinión de BrassLoff (1912) p. 675, cuando afirma que "In den Fragm. Vatic. ist er nicht exzerpiert, was sich aus der Entstehung dieser Rechtssammlung in der westlichen Reichshälfte erklärt”.

50 Cf. Viarengo (2009a) p. 40.

51 Véase infra, 3.

52 En detalle Wegmann Stockebrand (2017a) pp. 115 ss.; Wegmann Stockebrand (2018) pp. 97 ss.
} 
Así lo expresa en términos claros y precisos Gayo en sus Institutiones: al explicar en qué consiste este genus de obligatio ex contractu ${ }^{53}$, el maestro antoniniano menciona únicamente la mutui datio ${ }^{54}$, para luego dudar del carácter contractual (no así del real) de la solutio indebiti, representando esta, por decirlo de alguna manera, una obligación real extracontractual: el solvens que paga por error una deuda que no existe, quiere extinguir una obligación más que hacerla nacer, por lo que no cabría hablar de un contractus, pero el accipiens se obliga de todos modos re, ya que ha adquirido el dominio de las especies dadas en pago, al modo del mutuario (ac si mutuum accepisset) ${ }^{55}$. Por su parte, a propósito del tratamiento del nomen transscripticium, la obligatio litteris contracta (el así llamado contrato literal), Gayo distingue explícitamente dicha figura del nomen arcarium, un mutuo propiamente tal anotado solo para efectos probatorios (no constitutivos) en el codex accepti et expensi del acreedor con el consentimiento del deudor, señalando que este último nace re y, con ello, confirmando la idea de que el re contrahere se identifica con la dación mutuaria ${ }^{56}$. En las Instituciones gayanas no se encuentra, pues, referencia alguna a causas de obligatio re contracta distintas del mutuo, y no hay razones de peso para pensar que se trate de una omisión o laguna del palimpsesto veronés sobre este punto ${ }^{57}$, más allá de ideas preconcebidas sobre la sistemática del derecho contractual romano que carecen de suficiente apoyo textual ${ }^{58}$.

La noción de obligatio re contracta de que dan cuenta las Gai Institutiones se aprecia con igual claridad en otras fuentes de época clásica, como es el caso de Quinto Mucio Escévola, quien, a través del comentario de Pomponio a la obra del jurista tardo-republicano y a propósito del tratamiento de las causae credendi, nos informa que se contrae una obligación re (re contraxerimus), a saber, por medio de la mutui datio ${ }^{59}$. En efecto, el texto, en su versión original muciana, anterior a la muy probable intervención de Pomponio (quien

\footnotetext{
53 Gai. 3,89: Et prius videamus de his, quae ex contractu nascuntur. harum autem quattuor genera sunt: aut enim re contrahitur obligatio aut verbis aut litteris aut consensu.

54 Gai. 3,90: Re contrahitur obligatio velut mutui datione (...). Sobre el significado de la partícula velut, que no siempre tiene el significado de "por ejemplo", sino que también puede ser traducida como "a saber", WEGMANN Stockebrand (2017a) pp. 131 ss.

55 Gai. 3,91: Is quoque, qui non debitum accepit ab eo, qui per errorem soluit, re obligatur; nam proinde ei condici potest si paret eum dare oportere, ac si mutuum accepisset (...) sed haec species obligationis non videtur ex contractu consistere, quia is, qui solvendi animo dat, magis distrahere vult negotium quam contrahere. En detalle sobre esta cuestión, desde la perspectiva del autor, Wegmann Stockebrand (2017b) pp. 85 ss.

56 Gai. 3,131: Alia causa est eorum nominum, quae arcaria vocantur. in his enim rei, non litterarum obligatio consistit, quippe non aliter valent, quam si numerata sit pecunia; numeratio autem pecuniae rei facit obligationem. qua de causa recte dicemus arcaria nomina nullam facere obligationem, sed obligationis factae testimonium praebere. Sobre el nomen arcarium véase THILO (1980) pp. 130 ss.; GrÖSCHLER (1997) pp. 76 ss. Testimonios documentales en TPSulp. 60-65 (= CAMOdECA (1999) pp. 151 ss.).

57 Sí ven aquí una omisión o laguna MASCHI (1971) pp. 690 ss.; QuAdrato (1979) p. 69. Ambos autores carecen, empero, de suficiente apoyo en las fuentes para tal conjetura.

58 Plantean ciertas dudas sobre un reconocimiento por parte del ius civile de causas de obligatio re contracta distintas del mutuo, hablando de supuestas obligationes re contractae del derecho de gentes o impropias, TALAMANCA (1990) pp. 547 ss.; y GUARINO (2001) pp. 855 ss. Nada de esto encuentra fundamento en las fuentes jurídicas romanas.

59 D. 46,3,80 (Pomp. 4 ad Q. Muc.): Prout quidque contractum est, ita et solvi debet: ut, cum re contraxerimus, re solvi debet: veluti cum mutuum dedimus, ut retro pecuniae tantundem solvi debeat (...).
} 
habría añadido la alusión a las obligationes consensu contractae y el consiguiente dissensus como modo de extinguir las obligaciones), con toda seguridad debió tratar las tres posibles causas de certum dare oportere (re, verbis y litteris certum dare), es decir, los fundamentos de la entonces relativamente reciente legis actio per condictionem ${ }^{60}$, por lo cual necesariamente tenía que referirse a la mutui datio: el mutuo es el único contrato que genera un re certum dare oportere ${ }^{61}$.

Lo mismo puede decirse respecto de la noción de obligatio re contracta contenida en el comentario de Paulo al edicto del pretor urbano ${ }^{62}$. Si bien el mutuo no aparece expresamente mencionado en el texto paulino, es dable sostener que el jurista tardo-clásico alude implícitamente a él: de la lectura de la fuente se desprende que el nacimiento re de una obligación contractual (se emplea el verbo contrahere) supone la entrega translaticia de dominio de una cosa (datio rei), y no de cualquier cosa, sino de una cantidad determinada de bienes fungibles (res, quae pondero numero mensura constant), como se manifiesta en la mera mención de una cantidad cierta, un certum (con toda verosimilitud, de dinero), sin especificar, para restituir otras tantos del mismo género (tantundem eiusdem generis). Vale decir, se trata de una obligación de restitución, unilateral (solo el accipiens se obliga), que se hace valer por medio de una acción de estricto derecho, limitada al quanti ea res est (se excluye expresamente la posibilidad de demandar veinte, si solo se dieron diez), que no es sino la condictio. Pues bien, en derecho romano existe una sola figura negocial que reúne todas las características recién enunciadas, y no es otra que el mutuo: la mutui datio implica una transferencia de dominio de una cierta cantidad de bienes fungibles, que opera credendi causa, generando en el accipiens una obligación estrictamente restitutoria por el tantundem, por lo que no admite el pacto de intereses, como ocurriría en el caso de exigir la restitución de veinte cuando solo se prestaron diez ${ }^{63}$. Luego, Paulo está hablando, al igual que Quinto Mucio Escévola, de un re certum dare oportere y, por tanto, del contrato de mutuo.

En síntesis: el análisis de las fuentes jurídicas romanas que emplean el sintagma re contrahere en alguna de sus formas conduce a la conclusión -a nuestro juicio inequívocade que la obligatio re contracta es identificada sin excepción con la mutui datio. Lo dicho significa que la así llamada categoría del contrato real romano queda acotada al mutuo, con exclusión de cualquier otra figura, sin que para ello importe que tal o cual negocio nazca por medio de la entrega no translaticia de dominio (y, por tanto, de un facere en vez de un dare) de especies o cuerpos ciertos, como ocurre en el commodatum, el depositum y el pignus. La simple concurrencia del acto material de entrega de una res en la constitución de una relación obligatoria no tenía para los romanos una significación técnica concreta, ya

\footnotetext{
60 Cf. Cannata (1970) pp. 443 ss; Cannata (2008) pp. 61 ss.

${ }^{61}$ Cf. Cic., Pro Rosc. com. 4,13; 5,14: Pecunia petita est certa; cum tertia parte sponsio facta est. Haec pecunia necesse est aut data aut expensa lata aut stipulata sit. En detalle sobre esta cuestión, desde la perspectiva del autor, Wegmann Stockebrand (2017a) pp. 34 ss.; Wegmann Stockebrand (2018) pp. 109 ss.

62 D. 2,14,17pr. (Paul. 3 ad ed.): Si tibi decem dem et paciscar, ut viginti mihi debeantur, non nascitur obligatio ultra decem: re enim non potest obligatio contrahi, nisi quatenus datum sit.

${ }^{63}$ Cf. D. 12,1,11,1 (Ulp. 26 ad ed.). En este sentido ya Brasiello (1930) p. 583: "Pei classici che si potesse contrarre un' obligatio re oltre la somma trasmessa egualmente non era ammissibile"; TALAMANCA (1990) p. 541: "l'obbligazione sorge nei limiti in cui è avvenuta la datio".
} 
que la traditio es, considerada en sí misma, un acto por así decirlo jurídicamente insípido: el efecto que produzca en el mundo del derecho dependerá no tanto de ella misma considerada en abstracto, sino que más bien de su causa, pudiendo transferir el dominio, la possessio ad interdicta o la mera detentio o possessio naturalis sobre un bien, según cuál sea su fundamento concreto ${ }^{64}$. Así, fuera de la circunstancia que tanto el mutuo como el comodato, el depósito y la prenda nacen de la traditio de una cosa en sentido lato, entre estos negocios hay poco o nada en común que permita subsumirlos en una misma categoría contractual ${ }^{65}$.

Únicamente en las res cottidianae es posible encontrar un antecedente -por lo demás, mucho más vago y equívoco de lo que suele asumirse en doctrina- de una supuesta categoría de los contratos reales romana que incluya no solo el mutuo, sino que también el comodato, el depósito y la prenda. Después de una explicación del re contrahere que, al margen de diferencias estilísticas, equivale en sus aspectos esenciales a la contenida en las Gai Institutiones (esto es, limitada a la mutui datio) ${ }^{66}$, se afirma que el comodatario, el depositario y el acreedor prendario también (quoque) estarían obligados en virtud de una cosa (re), a saber, a la restitución de la res ipsa ${ }^{67}$. De aquí deriva la común atribución de paternidad de la así llamada categoría de los contratos reales al autor de las res cottidianae, muy probablemente el propio Gayo ${ }^{68}$.

Sin embargo, creemos que la interpretación habitual de los pasajes recién referidos de las res cottidianae no da cuenta del verdadero sentido y alcance de la reflexión de su autor sobre la obligación contraída re. En D. 44,7,1,3-6 no se encuentra argumento textual alguno a favor de la afirmación de que la obligatio re contracta clásica habría ampliado sus márgenes de manera tal de ya no estar restringida a la dación mutuaria, llegando a ser omnicomprensiva de todos los contratos que nacen de la entrega material de una cosa sin más, vale decir, el comodato, el depósito y la prenda. En efecto, el autor de las res cottidianae es particularmente escrupuloso al reservar el empleo del sintagma técnico re contrahere al mutuo (como toda la jurisprudencia clásica), mientras que para las obligaciones estrictamente restitutorias del comodatario, el depositario y el acreedor pignoraticio, que se hacen valer por medio de acciones honorarias (actiones commodati, depositi y pigneraticia in factum conceptae), limitadas al simple valor de las cosas entregadas (quanti ea res erit) y, por tanto, con toda probabilidad construidas según el modelo formular de la condictio ${ }^{69}$, emplea ex-

\footnotetext{
64 Plantea correctamente la cuestión Perozzi (1928) p. 32 (n. 1): "La frase: contratto che si fa colla cosa (re) non significa infatti nulla; ed è enorme in ogni caso riassumere in un'unica categoria per il modo di perfezionamento contratti che si perfezionano colla trasmissione del dominio e contratti che si perfezionano dando una cosa, di cui il dante conserva la proprietà e il possesso o sempre o agli effetti almeno dell'usucapione come nel pegno".

65 Así ya Schulz (1951) p. 469: “(..) otherweise the contracts assembled in this group have nothing in common”. En términos similares QUADRATO (1979) p. 78, quien se pregunta por "le ragioni di presenze così eterogenee in una stessa categoria”.

66 D. 44,7,1,2 (Gai. 2 res cott.): Re contrahitur obligatio mutui datione (...).

67 D. 44,7,1,3-6 (Gai. 2 res cott.): 3. Is quoque, cui rem aliquam commodamus, re nobis obligatur (...). 5. Is quoque, apud quem rem aliquam deponimus, re nobis tenetur (...). 6. Creditor quoque, qui pignus accepit, re tenetur (...).

68 Así p. ej. D’Ors (1951) p. 267; D’Ors (1975) pp. 7 ss. Sobre la paternidad gayana de las res cottidianae véase por todos MARTINI (2012) pp. 171 ss.

69 Ya Pernice (1873) pp. 429 ss., hablaba a este respecto de kondiktionenartige Klagen. En el mismo sentido KASER (1935) pp. 65 ss.
} 
presiones más genéricas e imprecisas, como re obligatur y re tenetur. De hecho, las acciones in factum (los clásicos hablaban a este respecto de actione teneri) de que dispone el comodante, el depositante y el deudor pignoraticio son las únicas que se refieren a la restitución de la cosa (reddere); las acciones de buena fe concebidas en el derecho para el comodato y el depósito (no hay constancia de una acción pignoraticia de buena fe en época clásica) aluden en términos genéricos a todo aquello que debe darse o hacerse conforme a la buena fe y, por tanto, facultan al iudex para condenar sobre la base del interés del acreedor (id quod interest), con independencia del valor económico de la cosa debida y sin referencia explícita a un reddere de la misma ${ }^{70}$.

De esta manera, si en las res cottidianae se advierte cierta asimilación entre el mutuo, por una parte, y el comodato, el depósito y la prenda, por la otra, ello obedece no a una supuesta agrupación de estas cuatro figuras en una misma categoría contractual, sino que a la semejanza que existe entre las obligaciones contraídas, respectivamente, por el mutuario, el comodatario, el depositario y el acreedor pignoraticio, y las acciones para hacerlas valer, que no es lo mismo exactamente: todos estos deudores tienen una obligación estrictamente restitutoria, limitada al simple valor de las cosas recibidas, que en el caso del mutuario se exige por medio de una acción civil (la condictio), mientras que en los otros tres, ello ocurre través de acciones honorarias construidas según el modelo de aquella. Luego, el comodatario, el depositario y el acreedor pignoraticio solo pueden ser considerados como obligados re si se usa esta expresión en un sentido amplísimo y, por ende, muy débil y atécnico ${ }^{71}$. Para el autor de las res cottidianae, la obligatio re contracta propiamente tal sigue limitada al mutuo: re contrahitur obligatio mutui datione ${ }^{72}$.

Ahora bien, esta noción muy restringida de re contrahere contrasta abiertamente no solo con la idea de contractus re desarrollada en el seno de la tradición del ius commune, sino que también -al menos a primera vista- con la idea de re obligari que parecieran contener los libri regularum de Herenio Modestino, cuestión que pasamos a tratar a continuación.

\section{RE OBLIGAMUR, CUM RES IPSA INTERCEDIT}

En el acápite precedente hemos visto que la jurisprudencia clásica coincide en que la obligatio re contracta encuentra su causa única y exclusivamente en la mutui datio: no hay texto alguno, ya sea dentro o fuera de la compilación justinianea, en el que se emplee el sintagma re contrahere respecto de negocios distintos del mutuum. El sentido impropio en el cual se utiliza la vaga terminología re obligari o re tenetur (en ningún caso re contrahere)

\footnotetext{
70 Sobre la duplicidad de acciones en el comodato y el depósito véase KranjC (2005) pp. 127 ss.; VerOnESE (2011) pp. 239 ss.

71 Así ya WubBe (1967) pp. 504 ss.; Wubbe (1990) p. 119: "La responsabilità introdotta con le nuove actiones in factum conceptae abituerà $i$ giuristi all'idea che il detentore, siccome sarà debitore ove non restituisca la cosa, ha l'obbligazione contrattuale di restituire. Si tratta di una specie di riflesso (...). Così depositario, comodatario e creditore pignoratizio potrebbero, a partire del momento in cui rivecono la cosa, essere considerati debitori, obligati re in un senso debolissimo di tale espressione".

72 En detalle sobre esta interpretación del texto de las res cottidianae WEgMANN STOCKEBRAND (2017a) pp. 218 ss.; Wegmann Stockebrand (2019b) en prensas.
} 
en las res cottidianae respecto de la obligación estrictamente restitutoria del comodatario, el depositario y el acreedor pignoraticio, análoga a la obligación contraía por el mutuario, no implica una ampliación de los márgenes del re contrahere hasta el punto de abarcar toda relación obligatoria ex contractu nacida de una entrega y, por consiguiente, identificable con aquello que desde el ius commune medieval hasta hoy representa la noción de contrato real.

En este contexto, la lectura de los libri regularum de Modestino causa perplejidad. En efecto, en todo el corpus de iura encontramos un único texto del cual pareciera desprenderse una noción de obligatio re contracta que, en lo sustancial, coincide con la moderna noción de contrato real. Se trata de:

D. 44,7,52pr.-1 (Mod. 2 reg.): Obligamur aut re, aut verbis, aut simul utroque, aut consensu, aut lege, aut iure honorario, aut necessitate, aut ex peccato. 1. Re obligamur, cum res ipsa intercedit.

Un análisis detallado de todas y cada una de las cuestiones tratadas en el principium del fragmento citado desbordaría los márgenes del presente estudio, por lo que hemos de contentarnos con algunas observaciones generales. En primer lugar, hay que tener presente que estamos frente a un texto extraído de los regularum libri $X$ de nuestro jurista, obra que lamentablemente hasta ahora no ha sido objeto de una investigación pormenorizada ${ }^{73}$. En cuanto a su fecha de redacción, con seguridad es posterior a la muerte de Antonino Caracalla (217) y, por tanto, a la concesión de ciudadanía romana y consiguiente extensión de la aplicación del derecho romano a todos los habitantes libres del imperio con excepción de los dediticios, el año $212^{74}$. La obra se caracteriza por la formulación de reglas jurídicas abstractas y principios generales, siguiendo un orden sistemático bastante peculiar ${ }^{75}$. Un vistazo general a los fragmentos de los libri regularum conservados en el Digesto hace patente su carácter eminentemente didáctico, a un nivel más bien elemental. Lo anterior se deduce, por ejemplo, de la presencia de partes con marcado tono teorizante ${ }^{76}$, empleo de la primera persona plural típica de la literatura isagógica ${ }^{77} \mathrm{y}$, sobre todo, abundancia de definiciones ${ }^{78}$ y una serie de clasificaciones y distinciones con la utilización reiterada de determinadas construcciones estereotipadas ${ }^{79}$. A mayor abundamiento, algunas de las distinciones contenidas en los libri regularum siguen muy de cerca el método de los libri differentiarum ${ }^{80}$. No

\footnotetext{
73 Una visión panorámica de la obra en Wieacker (1960) pp. 60 ss.; Schulz (1961) p. 224; Liebs (1976) pp. 234 ss.; Liebs (1997) p. 198; Viarengo (2012) pp. 12 ss.

74 Así se desprende de D. 1,9,3 (Mod. 6 reg.), texto en el cual Modestino habla de Divus Antoninus.

75 LiEBS (1997) p. 198.

76 P. ej. D. 1,3,7 (Mod. 1 reg.); D. 1,3,40 (Mod. 1 reg.); D. 23,2,1 (Mod. 1 reg.). Cf. Liebs (1976) p. 227.

77 P. ej. D. 17,2,4pr. (Mod. 3 reg.): (...) nos dubium non est. Cf. Liebs (1976) p. 228 (n. 168); ViarengO (2012) p. 13.

78 Por ejemplo la definición de matrimonio en D. 23,2,1 (Mod. 1 reg.); de estupro en D. 48,5,35pr. (Mod. 1 reg.); de adopción y adrogación en D. 1,7,1,1 (Mod. 2 reg.).

79 P. ej. a través del empleo de altera...altera en D. 1,7,1,1 (Mod. 2 reg.); de aut...aut... en D. 1,3,40 (Mod. 1 reg.); D. 44,7,52pr. (Mod. 2 reg.); D. 45,1,100 (Mod. 8 reg.); de et...et... en D. 4,6,32 (Mod. 9 reg.); D. 17,2,4pr. (Mod. 3 reg.); de quae...quae... und quaedam...quaedam... en D. 50,17,196 (Mod. 8 reg.); de vel... vel... en D. 18,1,62,1 (Mod. 5 reg.); o de vel...sive... en D. 46,6,7 (Mod. 6 reg.).

80 Se estructuran sobre la base de la differentia D. 1,7,1,1 (Mod. 2 reg.); D. 48,5,35pr.-1 (Mod. 1 reg.); D. 50,17,196 (Mod. 8 reg.). Cf. Liebs (1976) p. 227 s.; WieACKer (2006) p. 148; Viarengo (2012) p. 14.
} 
es casualidad entonces que se haya hablado de una predilección escolástica de Modestino por las distinciones ${ }^{81}$. De ahí que no quepa duda acerca del carácter didáctico de esta obra, con todas las consecuencias que ello acarrea para la interpretación de su contenido ${ }^{82}$.

El principium del fragmento presenta una clasificación de las fuentes de las obligaciones (causae obligationum, según el lenguaje de los clásicos), aunque de modo extremadamente asistemático, al menos para estándares modernos ${ }^{83}$. A todas luces, el esquema planteado por Modestino es más amplio que el gayano, al ofrecernos nada menos que ocho posibles causas de obligación, frente a la dicotomía contractus-delictum de $\mathrm{Gayo}^{84}$ : según nuestro jurista, una obligación puede nacer por medio de una cosa (re), por medio de una promesa formal verbal (verbis), a través de ambos elementos simultáneamente (simul utroque), por el consentimiento (consensu), en virtud de la ley (lege), del derecho pretorio (iure honorario), de la necesidad (necessitate) o de un delito (ex peccato). Merece destacarse la circunstancia que el texto no contiene referencia expresa alguna al contrato como causa de obligación; sin embargo, este se encuentra implícito: las formas ablativas re, verbis y consensu ${ }^{85}$ deben remitirse al contrahere ${ }^{86}$, no representando la exposición de Modestino bajo este último respecto nada nuevo.

Particularmente interesante para nuestro estudio es la construcción simul utroque, la cual se refiere más allá de toda duda al mutuum cum stipulatione, el así llamado negocio re et verbis ${ }^{87}$. Como se sabe, en derecho romano tanto la estructura de la dación mutuaria (nacimiento de una obligación credendi causa por medio de datio rei) como la fórmula de la condictio (acción estrictamente restitutoria, limitada al quanti ea res est) imposibilitaban que del solo mutuo pudiera surgir la obligación de pagar intereses (usurae), careciendo esta de causa. Ahora bien, como el cobro de intereses constituía, de hecho, el corazón de la industria financiera romana, el mutuum era acompañado generalmente por una stipulatio, la cual tenía la virtud de hacer nacer verbis la obligación de pago de intereses, con total independencia de la cantidad que efectivamente hubiera sido transferida al mutuario. De esta manera se podía contraer válidamente ante el ius civile una obligación de restitución de una cantidad mayor de aquella dada en mutuo bajo la forma de una estipulación (mutua pecunia in stipulatum deducta) ${ }^{88}$.

De las fuentes jurídicas de carácter técnico conservadas se desprende que los clásicos vieron en este esquema negocial solo una causa obligationis (unus contractus est), a saber, la

81 Brassloff (1912) p. 675.

82 Cf. Schmidlin (1970) p. 127; Viarengo (2012) p. 13.

83 Cf. Mayer-Maly (1967) p. 385; Viarengo (2009a) p. 102. D’Ors (1951) p. 300, habla de un "abigarrado catálogo". En opinión de TAlamanca (2003) p. 94, falta aquí "una terminologia ben delineata, come quella che -fissata in Gai. 3,89- concerneva i quattuor genera delle obligationes contractae".

${ }^{84}$ Gai. 3,88: (...) omnis enim obligatio vel ex contractu nascitur vel ex delicto. Cf. Gai. 4,2.

85 La obligatio litteris no es mencionada, seguramente por haber caído en desuso. Tampoco aparece en las res cottidianae, por el mismo motivo.

86 Cf. Gai. 3,89; D. 44,7,1,1 (Gai. 2 res cott.); I. 3,13,2.

87 Cf. además de la fuente citada, D. 12,1,9,4 (Ulp. 26 ad ed.). Una exégesis detallada en Talamanca (2003) pp. 101 ss.

88 Cf. GrösChler (2006) p. 261. 
stipulatio $^{89}$. Dicho en otros términos: el así llamado negocio re et verbis es, en realidad, una obligatio verbis contracta (específicamente una stipulatio in dando), no una re contracta. Según este modelo, entonces, la numeratio pecuniae no es otra cosa que la ejecución por parte del promissor de la prestación de dar debida al stipulator, operando solvendi causa en vez de contrahendi causa.

Desde esta perspectiva, llama la atención que Modestino hable de una obligación restitutoria contraída simultáneamente re (por mutuo) y verbis (por estipulación), lo que D'Ors no dudó en calificar como un "monstruo bifronte" 90 y ha dado lugar a sospechas de interpolación ${ }^{91}$. Como sea, haya o no Modestino afirmado aquí la existencia de una obligación nacida re et verbis, lo cierto es que no encontramos en el Digesto fuente alguna de este jurista que reconozca tal especie singularísima de relación obligatoria fuera de este muy asistemático catálogo de causae obligationum ${ }^{92}$. El así llamado negocio re et verbis, que tantos dolores de cabeza ha provocado a los romanistas, aparece mencionado por Modestino únicamente en este desordenado catálogo de causas de obligación elaborado con fines didácticos, y en ningún otro lugar.

Con todo, no podemos desconocer el hecho que los documentos de la praxis parecieran dar cuenta de, al menos, una representación de las cosas por parte de los operadores del mercado financiero -básicamente prestamistas y deudores- en el sentido que el mutuum cum stipulatione habría implicado que la obligación de restituir el dinero prestado nacía no solo ex stipulatione, sino que también ex mutui datione ${ }^{93}$. Luego, bien podría decirse que el nacimiento de la obligación simultáneamente por medio de mutuo y estipulación, contradice en lo sustancial lo sostenido por la jurisprudencia clásica (al margen de este texto de Modestino), mas no la idea que de esta operación tenían quienes tomaban parte activa en el tráfico financiero.

A partir de lo expuesto precedentemente sobre la individualidad de Modestino y la naturaleza de sus libri regularum, es posible sostener la hipótesis de que tal vez nuestro jurista quería aquí explicar la estructura de una figura tan singular como era el mutuum cum stipulatione a lectores de origen oriental $-\mathrm{y}$, por tanto, cuya lengua materna era el griego, no el latín- provistos de una formación jurídica más bien elemental, los cuales necesitaban interiorizarse en la profunda riqueza conceptual del ius civile que, a partir de la dictación de la constitutio Antoniniana, había pasado a ser su propio derecho. En efecto, la califica-

\footnotetext{
89 D. 45,1,126,2 (Paul. 3 quaest.); D. 46,2,6,1 (Ulp. 46 ad ed.); D. 46,2,7 (Pomp. 24 ad Sab.). Cf. p. ej. SACCONi (1989) pp. 39 ss.; Giuffrè (1989) pp. 85 ss.; Talamanca (2003) pp. 7 ss.

90 D'Ors (1951) p. 284.

91 Véase por todos Kaser (1975) p. 370 (n. 9); Talamanca (2003) pp. 93 ss.; Cannata (2008) pp. 92 ss.

92 No tiene nada que ver con el así llamado negocio re et verbis otro fragmento extraído de los libri regularum, D. 17,2,4pr. (Mod. 3 reg.): Societatem coire et re et verbis et per nuntium posse nos dubium non est. Aquí, el jurista se refiere a los modos en los cuales pueden manifestarse en consentimiento que se encuentra a la base del contrato de sociedad, una especie de obligatio consensu contracta. Lo dicho es sin perjuicio de admitir que el modo de expresarse es, una vez más, bastante ambiguo y confuso.

93 Así por ejemplo TPSulp. 51: (...) C. Novius Eunus scrippsi me accepisse \{ab\} mutua (...) et debere ei sesterta decem milia nummu, que ei redam (...). Cf. Wolf/Crook (1989) p. 18; MANTHE (1994) pp. 375 ss.; GrÖSCHLER (1997) p. 159 (n. 40). En este sentido, GRÖSCHLER (2006) pp. 273 ss., considera factible que en estricto derecho la obligación restitutoria pudiera nacer simultáneamente re y verbis ("Kombinationsmodell”).
} 
ción del mutuum cum stipulatione como una relación obligatoria que solo nace verbis, donde la numeratio pecuniae no es más que el cumplimiento de una stipulatio in dando ${ }^{94}$, parece ser una construcción demasiado abstrusa para quienes no están habituados a las sutilezas de la ars iuris romana y, de hecho, podría conducir a malos entendidos. La doble causación de la obligación re y verbis es, en cambio, más cercana a aquello que un lego se representaría mentalmente al entrar en contacto con esta clase de negocio y es, por lo demás, lo que se desprende de algunos documentos de la praxis. Un excelente conocedor de la cultura jurídica helenística, mucho menos refinada que la romana, no pudo pasar por alto esta circunstancia. Sin embargo, cuando se trata de resolver casos concretos no ya en su calidad de docente con especial predilección por el mundo oriental, sino que de iuris consultus de indubitada autoridad, no encontramos en las obras de Modestino ninguna otra referencia a una supuesta obligación re et verbis.

Y es así que llegamos al primer parágrafo del fragmento. Modestino intenta explicar a sus lectores la estructura de la primera clase de obligación, es decir, aquella contraída re, empleando los siguientes términos: Re obligamur, cum res ipsa intercedit. Nos obligamos por medio de una cosa, cuando esta misma "interviene" o "concurre". No existe fuente jurídica romana alguna que describa la obligación nacida re en términos tan amplios como aquí.

En primer lugar, hay que decir que la definición de Modestino es, a todas luces, equívoca, ya que rem ipsam intercedere podría referirse tanto al modo en que nace la obligación como al objeto de la misma ${ }^{95}$. Pero si el jurista estuviera hablando del objeto de la obligación, entonces cualquier relación obligatoria sería susceptible de ser calificada re, simplemente por el hecho que una cosa interviene o concurre (intercedit) de alguna manera; es decir, todas las obligaciones serían, en mayor o menor medida, actual o potencialmente, obligationes re (contractae). Sin embargo, sostener esto es absurdo: Modestino debió referirse aquí a algo más concreto, que no son sino las causae obligationum, como se desprende del principium del fragmento, aunque lo haya hecho recurriendo a una expresión tan poco feliz ${ }^{96}$.

En nuestra opinión, en lo fundamental resulta aplicable a la noción de re obligari contenida en esta fuente lo que dijimos más arriba sobre el así llamado negocio re et verbis. No consta en el derecho romano clásico una subsunción en la categoría del re contrahere de toda relación obligatoria nacida de la entrega de una cosa con independencia de la calificación jurídica de esta; la obligatio re contracta se engendra por medio de la mutui datio y de ninguna otra forma. Así lo debió creer el propio Modestino: cuando el jurista aclara el significado del re et verbis obligari en el tercer parágrafo del fragmento, es decir, específicamente a propósito del mutuum cum stipulatione, emplea los mismos términos que al explicar su idea de re obligari: Re et verbis pariter obligamur, cum et res interrogationi intercedit, consentientes in aliquam rem (nos obligamos conjuntamente por medio de una cosa y de las

\footnotetext{
94 Así GIUfFrè (1989) p. 101: “(...) la datio (...) costituiva, in pratica, la realizzazione della funzione socio-economica sottesa alla promessa di restituzione”.

95 Talamanca (2003) p. 97.

96 FerCia (2012) p. 47, habla a este respecto de una "categoria generalissima di re obligari".
} 
palabras cuando junto a la interrogación interviene o concurre también la cosa, consintiendo en alguna cosa) ${ }^{97}$.

Según las palabras de Modestino, nos encontramos ante una obligación real y verbal cuando junto a la interrogatio -la pregunta formal verbal dirigida por el stipulator al promissor- interviene o concurre una cosa: cum et res interrogationi intercedit. Ciertamente, la única manera en que una cosa puede intervenir como elemento engendrador de una obligatio es en cuanto objeto de una entrega: no es la cosa misma la que por sí sola hace nacer la obligación, sino el hecho de que es entregada. Y como estamos hablando del mutuum cum stipulatione, dicha entrega es, concretamente, la transferencia de una cierta cantidad de dinero (numeratio pecuniae). Luego, lo que Modestino quiere decir es que, en la especie, junto con la interrogatio formulada por el stipulator, este entrega materialmente el dinero al promissor, quien a su vez se obliga a restituirlo.

En el siguiente cuadro comparativo se aprecia a simple vista la coincidencia en el modo de expresarse del jurista en el primer y tercer parágrafo de la fuente: nos obligamos por medio de una cosa cuando esta misma concurre (re obligamur, cum res ipsa intercedit); nos obligamos conjuntamente por medio de una cosa y de las palabras cuando además de la interrogación concurre la cosa (re et verbis pariter obligamur, cum et res interrogationi intercedit).

\section{D. $44,7,52,1$ \\ Re obligamur, cum res ipsa intercedit \\ D. $44,7,52,3$ \\ Re [et verbis pariter] obligamur, cum [et] res \\ [interrogationi] intercedit}

Como puede verse, si omitimos las referencias directas a la estipulación en el tercer parágrafo (verba, interrogatio, la conjunción copulativa et y la expresión pariter, que remiten a la conexión en este caso entre re y verbis contrahere), este es prácticamente idéntico al primero, salvo que falta la partícula (res) ipsa, la cual en todo caso es innecesaria. De lo dicho resulta que la muy vaga e imprecisa locución cum res ipsa intercedit, que en una primera aproximación pareciera desbordar los márgenes del re obligari en general y del re contrahere en especial, da cuenta en realidad de un significado mucho más restringido de esta categoría contractual que coincide plenamente con el pensamiento clásico sobre la materia: utilizando el particular lenguaje de Modestino, la intercessio rei en cuanto modo de hacer nacer una relación obligatoria de naturaleza contractual no consiste sino en la mutui datio, en la medida que se refiere concretamente al mutuum (re obligamur) cum stipulatione (et verbis pariter obligamur). Traducida en términos jurídicos, la formulación re obligamur, cum res ipsa intercedit empleada por Modestino expresa, en el fondo, lo mismo que el re contrahitur obligatio mutui datione de Gayo. Nada más, pero tampoco nada menos.

Al igual que lo señalado precedentemente respecto del re et verbis obligari, la muy vaga e inexacta definición de obligatio re contracta contenida en D. 44,7,52,1 aparece únicamente en este catálogo de causae obligationum, escrito con toda probabilidad teniendo

\footnotetext{
${ }_{77}$ D. 44,7,52,3 (Mod. 2 reg.). La frase final (consentientes in aliquam rem) se refiere a la cosa no en cuanto su entrega constituye la causa de la relación obligatoria, sino que en calidad de objeto del negocio. Cf. TALAMANCA (2003) p. 98.
} 
en cuenta principalmente a actuales o potenciales lectores de origen oriental. No hay rastro alguno del empleo de esta noción amplísima de obligatio re contracta respecto de figuras distintas del mutuo, en Modestino ni en ningún otro jurista clásico. En definitiva, la muy simplificada y, a decir verdad, francamente imprecisa noción de re obligari presentada en D. 44,7,52,1 a sus muy probables discípulos grecoparlantes no afecta en nada la estructura clásica de obligatio re contracta restringida a la mutui datio, como atestiguan las fuentes desde Q. Mucio Escévola, pasando Pomponio y Gayo, hasta Paulo y, a nuestro entender, el propio Modestino.

\section{CONCLUSIONES}

A pesar de la imprecisión con la cual Modestino se expresa en su clasificación de las fuentes de obligación al exponer los rasgos esenciales del re obligari, no cabe duda de que en su obra el uso del ablativo causal re para el nacimiento de un vínculo obligatorio remite, expresa o implícitamente, a una dación mutuaria, aunque esté acompañada de una estipulación, como en el caso del así llamado negocio re et verbis. Un atento análisis de sus escritos contradice la idea, repetida como un mantra casi por inercia por la mayor parte de la doctrina romanista, en orden a que el derecho romano clásico habría conocido una categoría del re contrahere compuesta por todas aquellos contratos que se perfeccionan por medio de la entrega de una cosa sin más, es decir, una noción de obligatio re contracta que, sospechosamente, coincide perfectamente con nuestra idea de contrato real, a pesar de no contar con bases textuales en las fuentes antiguas, cuya exégesis es, en última instancia, lo que realmente importa en la investigación iusromanística.

En síntesis: si queremos ser justos con el aporte de Modestino a la iurisprudentia y liberarlo -aunque sea por un breve momento- de la sombra de su maestro Ulpiano, hay que decir que las opciones personales y científicas que lo individualizan -y honran- a nuestros ojos como jurista, lo hicieron merecedor del respeto, la admiración y la gratitud del mundo helenístico del siglo III d.C. sin que ello horadara su condición de iuris peritus de indubitada auctoritas. Modestino es el último jurista clásico, no el primer postclásico: su noción de contrato real es un ejemplo de ello.

\section{BIBLIOGRAFÍA CITADA}

Altmann, Josef (1955): "Die Wiedergabe römischen Rechts in griechischer Sprache bei Modestinus De Excusationibus", Studia et Documenta Historiae et Iuris, vol. XXI: pp. 1-73.

Babusiaux, Ulrike (2014): "Quod Graeci...vocant - Emblematischer Codewechsel in den Juristenschriften", en Inter cives necnon peregrinos. Essays in honour of Boudewijn Sirks (Göttingen, V \& R Unipress): pp. 35-59.

BALDUS, Christian (2012): "Il giurista in 'gabbia'? Osservazioni minime sull'individualità storica dei giuristi quale paradigma vecchio e nuovo", en Baldus, Christian, MiglietTA, Massimo, Santucci, Gianni y Stolfi, Emanuele (edit.), Dogmengeschichte und historis- 
che Individualität der römischen Juristen - Storia dei dogmi e individualità storica dei giuristi romani (Trento, Università degli Studi di Trento): pp. 7-21.

Brasiello, Ugo (1930): “Obligatio re contracta”, en Studi in onore di Pietro Bonfante II (Milano, Giuffrè): pp. 539-587.

Brasiello, Ugo (1944): "In tema di categorie contrattuali", en Studia et Documenta Historiae et Iuris, vol. X: pp. 101-149.

Brassloff, Stephan (1912): "Herennius Modestinus", Pauly-Wissowa Realencyclopädie der classischen Altertumswissenschaft, vol. VIII: pp. 668-675.

BRuns, Karl Georg (1909): Fontes iuris romani antiqui (Tübingen, Mohr).

Bussi, Emilio (1939): La formazione dei dogmi di diritto privato nel diritto comune (contratti, successioni, diritti di famiglia) (Padova, Cedam).

Camodeca, Giuseppe (1999): Tabulae Pompeianae Sulpiciorum (TPSulp.). Edizione critica dell'archivio puteolano dei Sulpicii I (Roma, Quasar).

Cannata, Carlo Augusto (1970): "La 'distinctio' re-verbis-litteris-consensu et les problèmes de la pratique", en Sein und Werden im Recht. Festgabe für Ulrich von Lübtow (Berlin, Duncker \& Humblot): pp. 431-455.

Cannata, Carlo Augusto (2008): Materiali per un corso di fondamenti del diritto europeo II (Torino, Giappichelli).

CoIng, Helmut (1985): Europäisches Privatrecht I. Älteres Gemeines Recht (1500 bis 1800) (München, C.H. Beck).

D’Ors, Álvaro (1951): "Re et verbis", en Moschetti, Guiscardo (edit.), Atti del Congresso Internazionale di Diritto Romano e di Storia del Diritto, Verona 27-28-29 IX 1948 III (Milano, Giuffrè): pp. 265-303.

D’Ors, Álvaro (1975): "Réplicas Panormitanas VI. Sobre la suerte del contrato real en el derecho romano", Revista de Derecho Notarial, vol. LXXXVIII: pp. 7-26.

Falcone, Giuseppe (2011): "Sistematiche gaiane e definizione di obligatio", en CAPOGrossi-ColognesI, Luigi y CURSI, Maria Floriana (edit.), Obligatio-obbligazione. Un confronto interdisciplinare (Atti del Convegno di Roma 23-24 settembre 2010) (Napoli, Jovene): pp. 17-52.

FERCIA, Riccardo (2012): 'Fiduciam contrahere' e 'contractus fiduciae'. Prospettive di diritto romano ed europeo (Napoli, Jovene).

GiUfFré, Vincenzo (1989): La 'datio mutui'. Prospettive romane e moderne (Napoli, Jovene).

Gokel, Julia Maria (2014): Sprachliche Indizien für inneres System bei Q. Cervidius Scaevola (Berlin, Duncker \& Humblot).

Gómez-Iglesias, Ángel (2004): "Herennio Modestino", en Domingo, Rafael (edit.), Juristas Universales I. Juristas antiguos (Madrid/Barcelona, Marcial Pons): pp. 214-216.

Gröschler, Peter (1997): Die tabellae-Urkunden aus den pompejanischen und herkulanensischen Urkundenfunden (Berlin, Duncker \& Humblot).

Gröschler, Peter (2006): "Die Konzeption des mutuum cum stipulatione”, Tijdschrift voor Rechtsgeschiedenis, vol. LXXIV: pp. 261-287.

GuARINO, Antonio (2001): Diritto privato romano (Napoli, Jovene, décimo segunda edición). 
HäUsLER, Adrian (2016): "Letztwillige Verfügungen in griechischer Sprache bei Q. C. Scaevola, Paulus und Modestinus", Zeitschrift der Savigny Stiftung für Rechtsgeschichte, romanistische Abteilung, vol. CXXXIII: pp. 420-444.

Honoré, Tony (1962): “The Severan lawyers: a preliminary survey”, en Studia et Documenta Historiae et Iuris, vol. XXVIII: pp. 162-232.

KASER, Max (1935): Quanti ea res est. Studien zur Methode der Litisästimation im klassischen römischen Recht (München, C.H. Beck).

Kaser, Max (1975): Das Römische Privatrecht II (München, C.H. Beck, segunda edición).

KRANJC, Janez (2005): "In ius und in factum konzipierte Klageformel bei der Leihe und bei der Verwahrung", en ERNST, Wolfgang y JAKAB, Eva (edit.), Usus antiquus juris romani. Antikes Recht in lebenspraktischer Anwendung (Heidelberg, Springer): pp. 127-161.

KRÜGER, Paul (1912): Geschichte der Quellen und Litteratur des Römischen Rechts (München/Leipzig, Duncker \& Humblot, segunda edición).

KunKel, Wolfgang (1967): Herkunft und soziale Stellung der römischen Juristen (Grazl Wien/Köln, Böhlau).

Lenel, Otto (1889): Palingenesia iuris civilis I (Leipzig, Tauchnitz).

Liebs, Detlef (1976): "Rechtsschulen und Rechtsunterricht im Prinzipat", Aufstieg und Niedergang der römischen Welt, vol. II, No 15: pp. 197-286.

Liebs, Detlef (1997): "Jurisprudenz", en Sallmann, Klaus (edit.), Die Literatur des Umbruchs. Von der römischen zur christlichen Literatur. 117 bis 284 n. Chr., en HerzoG, Reinhart y SCHMIDT, Peter (edit.), Handbuch der lateinischen Literatur der Antike IV (München, C.H. Beck): pp. 83-217.

Manthe, Ulrich (1994): "L'archivio puteolano dei Sulpicii", Labeo. Rassegna di diritto romano, vol. XL: pp. 370-381.

Martini, Remo (2012): "Gaio e le res cottidianae", Annali del Seminario Giuridico dell'Università di Palermo, vol. LV: pp. 171-188.

MaschI, Carlo Alberto (1971): "Tutela, fedecommessi, contratti reali (Omissioni nel manoscritto veronese delle Istituzioni di Gaio)", en Studi in onore di Edoardo Volterra IV (Milano, Giuffrè): pp. 667-774.

Maschi, Carlo Alberto (1973): La categoria dei contratti reali. Corso di diritto romano (Milano, Giuffrè).

Masiello, Tommaso (1983): I libri excusationum di Erennio Modestino (Napoli, Jovene).

Mayer - Maly, Theo (1967): "Divisio obligationum", The Irish Jurist, vol. II: pp. 375-385.

MünZER, Friedrich (1912): "Herennius”, Pauly-Wissowa Realencyclopädie der classischen Altertumswissenschaft, vol. VIII: pp. 661-662.

Orestano, Riccardo (1964): "Modestino Erennio", Novissimo Digesto Italiano, vol. X: pp. 819-820.

Parma, Aniello (2007): "Per la prosopografia di Q. Cervidius Scaevola”, en Cascione, Cosimo y Masi Doria, Carla (edit.), Fides Humanitas Ius. Studii in onore di Luigi Labruna $V I$ (Napoli, Editoriale Scientifica Italiana): pp. 4019-4028.

PERnICE, Alfred (1873): Labeo. Römisches Privatrecht im ersten Jahrhundert der Kaiserzeit I (Halle, Niemeyer). 
PerozzI, Silvio (1928): Istituzioni di diritto romano II (Roma, Athenaeum, segunda edición).

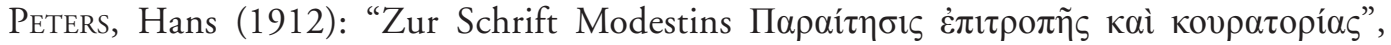
Zeitschrift der Savigny Stiftung für Rechtsgeschichte, romanistische Abteilung, vol. XXXIII: pp. 511-513.

Pichonnaz, Pascal (2017): "Plurilinguisme des juristes romains ... et des romanistes: quelques réflexions", Index. Quaderni Camerti di Studi Romanistici. International Survey of Roman law, vol. XLV: pp. 707-722.

Quadrato, Renato (1979): Le Institutiones nell'insegnamento di Gaio. Omissioni e rinvii (Napoli, Jovene).

SACCONI, Giuseppina (1989): Ricerche sulla stipulatio (Napoli, Jovene).

Schmidlin, Bruno (1970): Die römischen Rechtsregeln. Versuch einer Typologie (Köln/ Wien, Böhlau).

Schulz, Fritz (1934): Prinzipien des römischen Rechts (München/Leipzig, Duncker \& Humblot).

Schulz, Fritz (1951): Classical Roman Law (Oxford, Oxford University Press).

Schulz, Fritz (1961): Geschichte der römischen Rechtswissenschaft (Weimar, Hermann Böhlaus Nachfolger).

TalamanCA, Mario (1976): "Gli ordinamenti provinciali nella prospettiva dei giuristi tardoclassici”, en ARCHI, Gian Gualberto (edit.), Istituzioni giuridiche e realtà politiche nel tardo impero (III-V sec. d. C.). Atti di un incontro tra storici e giuristi. Firenze, 2-4 maggio 1974 (Milano, Giuffrè): pp. 95-246.

Talamanca, Mario (2003): "Una verborum obligatio e obligatio re et verbis contracta", Iura. Rivista internazionale di diritto romano e antico, vol. L: pp. 7-112.

Thilo, Ralf Michael (1980): Der Codex accepti et expensi im Römischen Recht. Ein Beitrag zur Lehre von der Litteralobligation (Göttingen, Muster Schmidt).

VERDAM, P.J. (1953): "Riflessioni sulla validità della categoria dei contratti reali", en Studi in memoria di Emilio Albertario II (Milano, Giuffrè): pp. 743-764.

Veronese, Benedetta (2011): "Buona fede e duplicità delle tutele processuali nei contratti di deposito e comodato", en Garofalo, Luigi (edit.), 'Actio in rem'e 'actio in personam'. In ricordo di Mario Talamanca II (Padova, Cedam): pp. 239-278.

Viarengo, Gloria (1996): L'excusatio tutelae nell'età del Principato (Genova, ECIG).

Viarengo, Gloria (2009a): Studi su Erennio Modestino. Profili biografici (Torino, Giappichelli).

Viarengo, Gloria (2009b): "Un piccolo repertorio latino-greco per i gradi di parentela", en Studi in onore di Remo Martini III (Milano, Giuffrè): pp. 917-935.

Viarengo, Gloria (2012): Studi su Erennio Modestino. Metodologie e opere per l'insegnamento del diritto (Torino, Giappichelli).

Volterra, Edoardo (1970): "L'opera di Erennio Modestino de excusationibus", en Studi in onore di Gioacchino Scaduto III (Padova, Cedam): pp. 581-604.

Wegmann Stockebrand, Adolfo (2017a): Obligatio re contracta. Ein Beitrag zur sogenannten Kategorie der Realverträge im römischen Recht (Tübingen, Mohr Siebeck).

Wegmann Stockebrand, Adolfo (2017b): "En torno al carácter (cuasi)contractual de la solutio indebiti en las Instituciones de Gayo", Revista de Estudios Histórico-Jurídicos, vol. XXXIX: pp. 85-110. 
Wegmann Stockebrand, Adolfo (2018): "Sobre el así llamado contrato real en las Instituciones de Gayo", Revista de Estudios Histórico-Jurídicos, vol. XL: pp. 97-122.

Wegmann Stockebrand, Adolfo (2019a): "Contrahere obligationem en el derecho romano clásico”, Revista de Derecho (Universidad Austral de Chile), vol. XXXII, No 2, en prensas.

Wegmann Stockebrand, Adolfo (2019b): "Causae credendi y obligatio re contracta en las res cottidianae", Revista de Estudios Histórico-Jurídicos, vol. XLI, en prensas.

WIEACKER, Franz (1960): Textstufen klassischer Juristen (Göttingen, Vandenhoeck \& Ruprecht).

WieACKeR, Franz (2006): Römische Rechtsgeschichte II (München, C.H. Beck).

Wolf, Joseph Georg y CROOK, John Anthony (1989): "Rechtsurkunden in Vulgärlatein aus den Jahren 37-39 n. Chr.", en Abhandlungen der Heidelberger Akademie der Wissenschaften. Philosophisch-historische Klasse (Heidelberg, Winter).

Wubbe, Felix (1967): "Gaius et les contrats reels", Tijdschrift voor Rechtsgeschiedenis, vol. XXXV: pp. 500-525.

Wubbe, Felix (1990): "I contratti reali alla fine della repubblica”, en Milazzo, Francesco (edit.), Contractus e pactum. Tipicità e libertà negoziale nell'esperienza tardo-repubblicana (Napoli, Editoriale Scientifica Italiana): pp. 109-121.

Zimmermann, Reinhard (1996): The Law of Obligations. Roman Foundations of the Civilian Tradition (Oxford, Oxford University Press). 